Revista de la red interuniversitaria de estudios sobre las literaturas rioplatenses contemporáneas en Francia

\title{
El novelazo diferido de Rodolfo Walsh
}

\section{Juan Pablo Luppi}

\section{OpenEdition}

\section{Journals}

\section{Edición electrónica}

URL: http://journals.openedition.org/lirico/2430

DOI: $10.4000 /$ lirico.2430

ISSN: 2262-8339

Editor

Réseau interuniversitaire d'étude des littératures contemporaines du Río de la Plata

\section{Referencia electrónica}

Juan Pablo Luppi, «El novelazo diferido de Rodolfo Walsh », Cuadernos LIRICO [En línea], 15 | 2016,

Puesto en línea el 25 septiembre 2016, consultado el 02 mayo 2019. URL : http:// journals.openedition.org/lirico/2430 ; DOI : 10.4000/lirico.2430

Este documento fue generado automáticamente el 2 mayo 2019.

\section{(c) (i) (9)}

Cuadernos LIRICO está distribuido bajo una Licencia Creative Commons Atribución-NoComercialSinDerivar 4.0 Internacional. 


\title{
El novelazo diferido de Rodolfo Walsh ${ }^{1}$
}

\author{
Juan Pablo Luppi
}

La idea de la novela en sí, su posibilidad, fue tomando una forma que no tenía. [...] Pero el trabajo realizado se notará, supongo, más adelante.

Diario de Rodolfo Walsh, enero de 1969

\section{El presente no ve la novela tras los libros}

En 1969, Rodolfo Walsh vive en Buenos Aires, tiene 42 años, prepara la tercera edición de Operación masacre (su clásico de 1957, reeditado en 1964), aún no está afiliado a ningún partido, sus dos hijas comienzan a militar en la juventud peronista. El año anterior ha participado en Cuba de congresos culturales guiados por el compromiso con las luchas populares y la desconfianza frente a valores burgueses como el intelectualismo; al volver de La Habana, se entrevista en Madrid con el ex presidente proscripto Juan D. Perón, quien le presenta al dirigente sindical Raimundo Ongaro. En mayo de 1968 asume la dirección del semanario de la CGTA (Confederación General del Trabajo de los Argentinos, central sindical opositora al gobierno militar-cívico de Juan C. Onganía impuesto por golpe de Estado en 1966) ${ }^{2}$. Un año antes de las insurrecciones civiles generadas por obreros y estudiantes y expandidas a la sociedad en Córdoba, Rosario y otras ciudades de Argentina, calificadas con el sufijo explosivo (cordobazo, rosariazo), entre los números 3 y 9 de CGT (del 16 de mayo al 27 de junio de 1968) Walsh publica siete notas sobre un crimen ocurrido en 1966 que involucraba al vandorismo (tendencia opuesta en la CGT dividida, integrada a la negociación con militares en el gobierno). Orientada por la pregunta política-detectivesca «¿Quién mató a Rosendo García?» (y por la respuesta diferida hasta el final, muy directa en la incriminación de Augusto T. Vandor), la campaña se extiende en una serie de notas sobre corrupción policial («La secta del gatillo y la picana»). Con ese material en el 69 Walsh arma un libro (en el sentido artesanal del trabajo de edición en que tenía larga experiencia, y a su vez porque pretende que sea ofensivo) que varía leve y significativamente la estructura de Operación masacre, con una nota preliminar que actualiza la intervención política contra el riesgo de que la forma novelesca mitigue la 
verdad denunciada. A cambio de la novela contratada por el editor Jorge Álvarez a fines de 1967, en 1969 Walsh entregará a la imprenta una antología acorde con sus viajes ( Crónicas de (uba), la tercera edición de Operación masacre, y el libro surgido de la campaña periodística que publica Tiempo Contemporáneo, ¿Quién mató a Rosendo?

Casi medio siglo después -cuando ¿Quién mató a Rosendo? (y la obra conjunta de Walsh enriquecida con parciales recuperaciones desde fines de los 80) puede ser leída más allá del riesgo de que la ficción aplaque la verdad- diversas poéticas argentinas actualizan la funcionalidad del proyecto narrativo de Walsh y confieren visibilidad a la novela allí imaginada, acaso imposibilitada pero también suscitada por la oscuridad de su presente. Al querer encauzar la velocidad de la revolución en el oficio meticuloso de leer/escribir, Walsh genera una poética irreductible a la ficción y a la estética, practicada como preparación de una novela, anotada, conversada, iniciada en borradores, que excede soportes, géneros y épocas. Editorialmente inexistente, esa novela reaparece por fragmentos en otros ciclos novelísticos del cambio de siglo, y puede complejizar la imaginación crítica sobre la poética política de Walsh. En esta primera parte indagamos las tensiones sobre lo nuevo y la novela que eclosionan hacia 1969, para encontrar la novela sin libro de Walsh expandida en ciertos libros argentinos que, hacia 2010 (como veremos en la segunda parte), actualizan la relación entre pasado y futuro que atraviesa cada presente.

El pasado se yuxtapone con el futuro al considerar 1969 como memoria del 69, signada por la pulsión de recomienzo y la expectativa de lo nuevo, que en ese año habría alcanzado a la vez su apogeo y su extenuación. A un cuarto de siglo, Altamirano confronta la cristalización del pasado con la exigencia de novedad: frente al «proceso de asimilación del gran suceso en el código del discurso militante» de «la izquierda maximalista», que pronto fijó el cordobazo como «el esbozo, sin dirección revolucionaria, de la insurrección», y limitó el discurso a «la representación de lo ya acontecido», Altamirano inquiere el momento en que la significación del suceso «se mantuvo flotante y libre [...], en que la expectativa de lo nuevo predominó sobre lo ya pensado y lo ya visto». La expectación «duró dos o tres años y se detuvo un día, entre 1972 y 1973», cuando Perón vuelve a la presidencia tras dieciocho años de proscripción (1994: 6-7)3. Así como se extendería hasta 1973, la epifanía de lo nuevo abarca el pasado reciente de 1969, signado por otra fecha emblemática: serían "catorce años prodigiosos», entre la revolución cubana (1959) y «la cascada de regímenes dictatoriales en América Latina» (1973), según la propuesta de Gilman para considerar los sesenta/setenta como época: «Un período en el que todo parecía a punto de cambiar» (2003: 35). En la periodización de Terán el espíritu modernizador surgiría con la resistencia peronista en 1956 y llegaría al esbozo insurreccional de 1969, como «la corriente de época en la cual, en un ambiente de criticismo y de experimentalismo, la categoría de 'lo nuevo' adquirió una marcada legitimidad» (2012: 276-278). Tal legitimidad define las prácticas del campo cultural que Terán destacaba en su clásico estudio sobre nuestros años sesentas, circunscriptos a la década 1956-1966: clima experimentalista, conflicto generacional, hibridez entre institución y márgenes ${ }^{4}$.

4 Walsh vive ese proceso en presente, y la superposición de velocidades dispares marca tensiones entre oficios literario y periodístico y acción política. La revolución altera el ritmo vital de quien se define por la falta de tiempo y la lentitud ideológica y estética. En 1965 siente que «en la hipótesis de seguir escribiendo, lo que más necesito es una cuota generosa de tiempo». Así lo confiesa públicamente en la nota autobiográfica que 
acompaña su cuento incluido en la antología Los diez mandamientos (Jorge Álvarez, 1966): «Soy lento: he tardado quince años en pasar del mero nacionalismo a la izquierda; lustros en aprender a armar un cuento, a sentir la respiración de un texto» (AA.VV. 1966: 11). Entre 1969 y 1973 la revolución desacomoda el biorritmo del escritor y lo impulsa al desarrollo de opciones laterales frente a la aceleración del presente. Entonces se habría vuelto acuciante la resistencia moral ante las mentiras de la ficción, el reparo contra la reducción de su obra al reino del azar y la imaginación, que provoca la advertencia sobre la lectura inocua en la «Noticia preliminar» de ¿Quién mató a Rosendo?: «Si alguien quiere leer este libro como una simple novela policial, es cosa suya. Yo no creo que un episodio tan complejo como la masacre de Avellaneda ocurra por casualidad. ¿Pudo no suceder?» (2003: 9). La velocidad política del 69 impone al escritor el límite de la representación. Si puede haber novela ya no será una ficción detectivesca sino un relato documental, abierto al pasado y al futuro, ofensivo en su tiempo y lugar, donde el ritmo novelesco no disipe la dimensión política del acontecimiento (no solo el crimen del 66 sino su ocultamiento, y el libro salido del semanario).

5 El escritor responde de modo sinuoso a la demanda de época, desfasado de las posibilidades de vida que puede configurar: cuando se acerca al gremialismo Ongaro desconfía de su obra reciente, cuando decide afiliarse a la militancia revolucionaria es padre de jóvenes militantes, cuando empieza a descreer de la novela el campo editorial le ofrece contrato para escribir una. En enero de 1969, con el encabezado «SITUACIÓN. DEFINICIONES», anota que ha vivido «a razón de 150 dólares mensuales» desde octubre de 1967, y que el incumplimiento del contrato implica una deuda con Jorge Álvarez de 2250 dólares. El cálculo deviene balance autoral y vital, referido a la producción de libros como trabajo que implica una ética ${ }^{5}$. Frente a la crisis económica doméstica, el escritor planea conchabarse (verbo gaucho que se adjudica, referido a trabajar como empleado) en la revista Panorama donde había colaborado en 1966-67 (justamente cuando reingresó a la prensa y abandonó el retiro que se había procurado tres años antes para escribir ficciones). El balance culmina con la obligación tensa de la novela, entre auto-mandatos e impedimentos no solo externos: «La deuda con Álvarez quedaría como caución de la novela que, a pesar de todo, debo escribir». En el Diario editado por Link sigue una reflexión titulada La novela, donde Walsh se explica los obstáculos materiales y subjetivos que impidieron «sumergirme en la novela y descontar el tiempo perdido» cuando lo intentó a partir de septiembre del 68: falta de rendimiento del tiempo, fatiga por el trabajo en CGT, desaliento por la momentánea derrota de Ongaro, y también «resistencias de tipo psicoanalítico, digamos», en la medida en que «la novela cuestiona mi vida, la vida de mi hermano, de mis amigos»; «el desistimiento» con que cierra la nota reflejaría «[1]a dificultad ante la Novela, la verdadera Neurosis que me produce» (2007: 123-125).

Libro de Walsh armado por otro (Link fecha el prólogo de la primera edición en diciembre de 1995 y el de la segunda en enero de 2007, a tres décadas de la muerte de Walsh), Ese hombre enriquece la textualidad abierta del proyecto con la materialidad de la notación que busca la novela y choca con el deber de verdad. Si esa búsqueda se hace legible hacia el cambio de siglo, el libro la muestra abierta desde principios de los 60. En 1962, los borradores desarrollan varios párrafos que ficcionalizan la experiencia cubana (el trabajo con Jorge Masetti en Prensa Latina durante 1960, en contacto cotidiano con la revolución), la mayoría de los cuales, nota Link, «están marcados, en el margen, con una 'N’ (¿novela?)». Al aparecer en el texto la mención de la cara de un hombre, el escritor anota «hacer de él un personaje»; al final de un tramo, bajo tachadura se lee «Próximo 
capítulo» (2007: 60 y 62, notas 27-29). La proyección de novela asoma en 1962, fragmentada y plagada de enmiendas y anotaciones. Al retomar esas escrituras en 1965 Walsh numera los fragmentos, como buscando forma de capítulos, y al margen anota: «Hilvanar cada chapitre, hacer un coso sólido» (82, nota 41).

Dispersas definiciones de lo indefinible arman la imaginación de la novela como un coso sólido hecho de partes cosidas, donde convertir personas en personajes y mezclar la ficción en lo real. Esta mezcla provoca la resistencia antinovelesca de Walsh, que no implica abandonar aquella imaginación. El antiguo término novela es el que elige Barthes, en sus cursos de 1978-1980, «por comodidad para sugerir la idea de una 'obra' que habla de su vínculo con la literatura, por una parte, y con la vida, por otra» (2005: 459). La intermitencia de ambas partes atraviesa el diario de la novela futura de Walsh, donde la notación busca el pasaje a la forma grande, tramitada entre deseo y ley, que Barthes vincula con los horarios de trabajo y la vida metódica (316-317, entre otras). Un proyecto novelesco puede surgir de la notación fragmentada del presente, aunque allí «no miento nunca (no invento nunca)» y por eso «no accedo a la novela». Antes un tejido vasto de ilusiones que un sostenimiento de la verdad del momento, la novela comenzaría «cuando se mezcla sin prevención lo verdadero y lo falso»: «llegar a hacer una novela [...] es en el fondo aceptar mentir, llegar a mentir (mentir puede ser muy difícil): mentir con esa mentira segunda y perversa que consiste en mezclar lo verdadero y lo falso». El desistimiento de Walsh frente a la novela no es mero abandono por la militancia sino resistencia contra lo inocuo de la ficción, como una modulación anticipada de la hipótesis barthesiana: «la impotencia para la novela (para su práctica) sería una resistencia moral» (Barthes 2005: 164; itálicas en original). En este sentido decíamos que la velocidad política impone al escritor el límite de la representación.

8 Frente al vértigo fechado en 1969, el biorritmo de Walsh acciona la proyección de una novela tensionada por la demanda de verdad. «Los hechos producidos en Córdoba y Rosario proveen a la novela de un nuevo 'centro' de verdad», anota a principios de junio de 1969: «Cuando cuarenta mil hombres y mujeres salen a la calle, como en Córdoba, un héroe es cualquiera» (2007: 139). A fines de noviembre tramita con amargura el tiempo dividido entre yo y otros, novela y política: «Durante cinco meses, he vivido para mantener lo que se podía mantener de la CGT; no he escrito casi una línea para mí; no he ganado un peso para mí; he ambulado de un lado a otro» (165). Desde su infancia Walsh nunca ha podido estar quieto; menos en 1969. En los desfasajes entre plan y realidad encuentra tiempo para pensar la novela, hacerla por fragmentos del pasado hacia el presente, entre personas y personajes, vida y ficción. Esa preparación de novela expone la resistencia moral, los impedimentos (tiempo/dinero), la contigüidad de literatura y vida que Barthes indagará a fines de los 70. En mayo del 69, la publicación de ¿Quién mató a Rosendo? cristaliza la pregunta del momento: «¿Ha renunciado a la literatura?». Walsh responde «De ninguna manera», destaca la productividad de «ese vaivén entre el periodismo y la literatura», y considera que las crónicas de Panorama «implicaban posibilidades literarias futuras, al margen de que confirmaban mi militancia política». Sobre la novela que, dice el entrevistador de Siete Días, «-todavía- no ha podido escribir» por el impedimento de «[e]se periodismo que él llamará 'de acción'", Walsh propone que «uno no escribe una novela sino que está dentro de ella, es un personaje más y la está viviendo». Señala la complicación de su novela empezada (como la menciona el entrevistador) porque "abarca épocas diferentes» y demanda «un enorme trabajo de documentación». A mediados de 1969, el escritor proyecta un relato que pueda avanzar 
en direcciones imprevistas frente a la crisis de la forma novelesca: «Yo creo que sí puedo escribir una novela, pero lo que está en crisis -al menos en lo que a mí atañe- es el concepto mismo de la novela» (2007: 141-143).

9 La percepción de que Walsh todavía no ha podido escribir una novela se había instalado en 1967, cuando Un kilo de oro -cuatro cuentos en línea con los seis de Los oficios terrestres (1965)- es recibido como mero agregado en una serie narrativa que no logra la forma editorial mayor. La reseña del diario $E l$ Mundo en octubre de 1967, titulada «RODOLFO WALSH. Le Reclaman una Novela» (43; mayúsculas en original), sanciona la velocidad del proyecto: «sus lentitudes anteriores -venir a Buenos Aires, encontrar un oficio, dedicarse a escribir- preparaban estas velocidades», en referencia a la producción apresurada (cataloga «Cartas» como «una novela comprimida» y «Los oficios terrestres» como «un resumen»). El reclamo no era original: semanas antes, Primera Plana titulaba su reseña con la catalogación de Los oficios y Un kilo como paratexto subsidiario de una obra pendiente: «El prólogo de la novela». Al recalcar lo que le falta a Walsh para consagrarse como escritor, tal recepción resulta sintomática del momento cultural en que «todo parecía a punto de cambiar». Gilman lee en 1967 lo que la historia política ubica en 1969, el brusco movimiento contradictorio implícito en toda culminación: «el apogeo y el fin de las posibilidades de nuevas consagraciones en el mercado», un «fenómeno de clímax y agotamiento casi inmediato» a partir del cual el campo literario trazó una línea divisoria entre escritores revolucionarios y consagrados $(2003: 31,93)^{6}$. En las reseñas y entrevistas de 1967 a 1970 (y aún después, hasta hoy) se hace evidente el límite en la valoración de Walsh, impuesto por la doble frontera de la estética, que valora el producto acabado (vendible) en forma de novela, y la política, que legitima la revolución y define el movimiento de la cultura.

10 La lectura peyorativa del éxito según criterios políticos o estéticos (asumida por el autor y replicada por la crítica) justificaría el mentado abandono de la literatura por la conversión del autor en escritor revolucionario. Sin embargo, Walsh se juega la vida en un sentido cotidiano, más acá de la muerte heroica, como posibilidad de vida de escritor no consagrado, con el horario organizado para subsistir con el oficio que domina, aunque (como dice sobre su novela empezada) «[v]olver a ello no depende de mí sino del mundo exterior» (2007: 143). La tarea de escribir está pegada a la de editar, armar, difundir revistas y libros: producir efectos. En febrero de 1970 anota «datos sobre el oficio de escribir» que son cifras de tiraje brindadas por «JA» (Jorge Álvarez). Con el tono íntimo de organizar esa estadística en función de la vida, la rutina y los hábitos, muestra la relevancia de los ritmos inciertos del mercado cultural, la vertiginosa inmediatez entre apogeo y agotamiento que Gilman ubica en 1967. Con buen criterio según el estado del campo editorial, Walsh considera «cifras por de más modestas» los 2600 ejemplares de Un kilo de oro vendidos en poco más de dos años (el saldo de 3404 ejemplares implica la expectativa de masividad que orientaba las apuestas editoriales). Atento al ritmo de la industria, el escritor-editor contextualiza las cifras y da precisión al desfasaje de 1970 con respecto al clímax inmediato anterior: «Hay que tener en cuenta que corresponden a un 'boom' ya definitivamente terminado» (2007: 184-185).

11 Si el tiraje en un lustro de La granada (2000 ejemplares) y Los oficios terrestres (2400) era bajo para la época, debía parecer más modesto en comparación con el millón de ejemplares superados en siete meses por el semanario CGT, como celebra su número 33 en diciembre de $1968^{7}$. Al asumir la dirección del medio opositor Walsh realiza la ambición que muchos intelectuales de los 60 vehicularon a nivel imaginario: rebelados «con 
encomiable vocación por lo social contra la especialización corporativa», «pretendieron dirigirse así fuere imaginariamente a sujetos sociales más amplios (la clase obrera, el pueblo)» (Terán 1991: 157). La crónica del número 46 de CGT, sobre el paro general del 30 de mayo del 69, estipula su destinatario como el sujeto colectivo que está protagonizando los cordobazos extendidos por diversas ciudades: «hombres y mujeres que se han lanzado a las calles en todas las ciudades del país», "los compañeros estudiantes que pelearon y cayeron en Corrientes, Resistencia, Rosario, Córdoba, Tucumán y Salta, y los que aguardan su hora en el resto del país», a ellos «queremos dirigirnos». Son los sujetos anónimos que Walsh hace hablar por escrito en sus crónicas para narrar el trabajo humano desde adentro, como resume en 1970 el plan de una nota sobre el servicio de aguas corrientes: deberá mostrar «su rutina, pero también sus ansiedades, expectativas, victorias y reveses, sus anécdotas, el pasado y el futuro» (2007: 190). Las voces de los trabajadores resuenan en la escritura del yo que las graba, el sujeto que debe conchabarse en el mercado periodístico, que en la intimidad anota sus propias ansiedades.

Sujetos, lugares, trabajo, historia forman una constelación que recorre el afán narrativo de Walsh en sus diversas formas. La dupla personas y hechos, que organizaba la estructura de Operación masacre, en ¿Quién mató a Rosendo? se fusiona y deviene posibilidad de narrar subjetividades históricas, personas vitalmente fundidas con hechos sociales y políticos reconstruidos ${ }^{8}$. Las vidas particulares (Livraga, Troxler en Operación, Raimundo o Blajaquis en Rosendo) impulsan una lectura de la historia social argentina, coherente con la exploración del plurilingüismo en las crónicas etnográficas sobre el noreste argentino y el conurbano bonaerense (diez notas en Panorama entre abril de 1966 y diciembre de 1967). El comienzo de ¿Quién mató a Rosendo? muestra la contigüidad entre escritura y vida, y expone la resistencia moral ante la mezcla de verdad y mentira. El primer capítulo, «Raimundo», hace el retrato con su voz editada; el segundo, «Avellaneda», amplía la toma con resonancias documentales de voz en off que hace la crónica histórica del lugar geográfico cultural, escenario del conflicto. Allí condensa en cuatro páginas las transformaciones urbanas entre el cierre de saladeros «cuando la fiebre amarilla» (1870) y el ascenso de «los nuevos caudillos con sus favores y matones» desde 1945 al presente (Walsh 2003: 25, 29). El movimiento narrativo es similar al que busca en las notas de lectura editadas al final de Ese hombre, vinculadas al cuento que podía ser primer capítulo de la novela9.

¿Quién mató a Rosendo? edita con apariencia de novela la campaña publicada en CGT; en el umbral Walsh solicita una lectura del libro que acompañe la potencia del periódico, su ampliación de la recepción cultural y la circulación impresa. Acaso esa condición anfibia un libro que parece una novela pero afirma que no lo es- incide en la incomodidad crítica para integrarlo junto con su autor en el sistema literario, como ocurre en la estructura del sentir que Dalmaroni propone para $1969^{10}$. Ese momento reuniría a los últimos modernos de la literatura argentina, en el mismo año en que la historiografía ubica la eclosión de la violencia política, «la turbulencia histórica durante la cual la literatura exorbita y descalabra una constelación de creencias». La dificultad de ubicar a Walsh en esa serie (en toda serie) motiva una nota al pie donde Dalmaroni desplaza de su objeto la argumentación que exigiría esa inclusión junto con la de Puig ${ }^{11}$. Atravesada por géneros diversos y temporalidades superpuestas, la obra de Walsh se extiende antes y después de los booms construidos por la cultura. Su libro del 69 se niega a ser solo una novela; ha cambiado el sesgo de lo nuevo con respecto a los cuentos que los reseñadores de 1967 veían como «prólogo de la novela» sin considerar la riqueza múltiple de prólogos y pre- 
textos que, al decir de Macedonio, se sienten novela. Crítica, crónica, entrevista, carta serían formas discursivas en busca de otras incomodidades, espacios fronterizos en el país y en los textos, trazados a partir de voces que habitan los lugares, como fotos/cartas que arman por fragmentos la historia común y la del yo que los hace hablar por escrito. A medio siglo de la investigación que lo propició, Rosendo puede ser leído como novela sin menoscabo de la verdad investigada; el proyecto se resignifica no ya en función de la revolución del contexto sino de lo revolucionario del texto, como podrá percibirse a partir de ciertas resoluciones narrativas de la novela argentina a comienzos del siglo XXI.

\section{El futuro lee la novela sin libro}

La demanda de los reseñadores de Un kilo de oro implica la reducción a la estética de la actitud del espectador, que desestima la poética desarrollada en la imaginación de una novela ${ }^{12}$. Frente al canon que limita a Walsh al monumento periodístico-político, incómodo para el sistema de consagración literaria porque le falta el producto acabado según las pautas de la cultura industrial, el proyecto lanza una acción poética, con decisiones técnicas y políticas por las que el sujeto es éticamente responsable. La novela posible, imaginada pero ilegible en 1969 , encauza con tensiones la mitología autoral que da continuidad al proyecto y dialoga con las transformaciones del ágora contemporánea, «desde la estética a la poética, más específicamente hacia la autopoética, hacia la producción del propio Yo público» (Groys 2014: 16). Bajo el corpus visible en la explosión editorial de la segunda mitad de los 60, como escombro de los booms y cordobazos, habría un silencioso e incompleto novelazo de Walsh, proyectado en el ambicioso plan narrativo que rastrea el sesgo político en la construcción de voces, pluraliza la destinación del texto y tramita la configuración autoral en la intersubjetividad del lenguaje. Diluida bajo la cristalización del monumento militante, la preparación de la novela configura una acción vital, ética, poética, no encuadrable en la estética o la política, que cobra resonancia en la literatura contemporánea.

15 El efecto de lo que Altamirano llama memoria del 69 (la tensión entre cristalización del pasado y demanda de lo nuevo) incide en la canonización de Walsh, centrada en «la tensión entre ficción y política, clave en la historia de nuestra literatura»: «Su obra está escindida por ese contraste», afirma Piglia (2013: 11) al prologar los Cuentos completos, y aunque valoriza la comprensión del escritor para «trabajar esa oposición y exasperarla», mantiene la dicotomía que ha fijado lo nuevo de Walsh en la no-ficción y las formas breves $^{13}$. Si para Piglia, como para el consenso de la crítica, «la marca de Walsh es la politización de la investigación» (15), cabe preguntar cómo esa marca es afectada por la ficcionalización de la investigación, por los modos de narrar la búsqueda de verdad. La transposición del documento a la narrativa expande la hibridez de géneros menores que no solo derivan hacia el cuento («Esa mujer» es el ejemplo priorizado por Piglia) sino hacia la novela, trazada en tensión con la demanda de verdad y los límites de lo novelesco, frente a la expectativa de lo nuevo y la aceleración revolucionaria.

Propia de su tiempo, la novela de Walsh sería antinovelesca, resistente a confundir verdad con mentira, plástica para mezclar voces y superponer tiempos. Como su autor al autodefinirse en la nota autobiográfica de 1966, sería una novela traída y llevada por los tiempos, «disponible para cualquier aventura, para empezar de nuevo, como tantas veces» (AA.VV. 1966: 10-11). Semejante narración, que empezara de nuevo cada vez, acorde a los cambios del presente, ofrecería una salida anacrónica del agotamiento de la ficción que John 
Barth declaraba en 1967, al detectar «ese estado de 'extenuación' que sobreviene cuando la ficción ha explorado aparentemente todo lo que puede explorarse en las convenciones de su escritura» (Littau 2008: 126). El estilo de Walsh se fuga de lo que Barth llamaba ficción posmodernista, porque recupera el afán de narrar procesos históricos, sin renunciar a procedimientos aptos para «romper la ilusión y toda posibilidad de identificación» (125). Es en esta ruptura donde la novela de Walsh no puede dejar de comenzar, porque entre tantas mezclas hay una que se resiste a cumplir, aquella que para Barthes (2005: 164) sería el comienzo de la novela, «cuando se mezcla sin prevención lo verdadero y lo falso». El desistimiento no es una renuncia a la novela o mera impotencia para su práctica, sino una pugna poética y política con las resistencias literarias, culturales, vitales en un tiempo de nuevos comienzos.

La oportunidad de leer entre los cuentos de Walsh novelas fragmentadas, diseminadas en distintos espacios y tiempos de enunciación, ha permitido separarlo de la lógica del canon para revalorizarlo por la generación de formas que serían novelas condensadas, disociadas de la forma libro. En la propuesta de Link, la obra adquiere sentido en la doble confrontación con los frentes en que la institución literatura pierde su autonomía: el mercado editorial que imprime su lógica a la producción latinoamericana, y la neovanguardia de los 60 que desbarata toda ilusión de neutralidad política. Leído como vanguardia a comienzos del siglo XXI, Walsh «propone un 'género' que ni Menard ni Bustos Domecq imaginaron: una novela sin ficción, una novela sin libro» (Link 2003: 289-291 ${ }^{14}$. Fuera de campo y sin soporte, la novela circula como notación minuciosa en torno a las capas significativas depositadas en la diacronía del idioma nacional. En el cruce de series y la superposición de capas, el proyecto diseña una «novela geológica», como titula Primera Plana la entrevista publicada en octubre de 1968, cuando el escritor llevaba tres meses «escribiendo una serie de historias [...] con la idea de fundirlas en una novela» (Walsh 2007: 110-112). Especie de apunte novelístico a dos voces, la entrevista proyecta la centralidad del lenguaje en la constelación sujetos/lugares/historia: «En la base de su plan está el lenguaje, las capas geológicas del habla rioplatense que han ido superponiéndose desde los días de la Organización». La demanda de verdad obliga a cruzar las historias particulares con la historia nacional, promoviendo la combinación de lo individual con lo social ${ }^{15}$. Tapado por novelones de Saer, Tizón, Viñas o García Márquez, el módico novelazo de Walsh sería una totalidad imposible hecha de fragmentos inestables (textos desperdigados en periódicos, entrevistas, borradores secuestrados, papeles recuperados, cartas íntimas y abiertas, libros hechos con material de prensa, libros de cuentos que no llegan a novela); desarrollada en el lenguaje, en la palabra propia mezclada con enunciados ajenos, esa dispersión hallaría unidad en la indagación de los lazos conflictivos entre verdad y ficción, política, economía y vida, pasado y futuro.

El plan de una historia mayor hecha de historias particulares, conectando personajes de distintos textos (que vimos asomar en los borradores a mediados de los 60 , como afán de hacer un coso sólido hilvanando capítulos), convive con el trabajo en el semanario CGT y las prevenciones contra los valores burgueses y la trampa intelectual. En agosto de 1968 Walsh anota su balance autocrítico frente al periódico y se afirma en el deseo de escribir: «El intelectual en su trampa. Cuatro meses [...] totalmente dedicado a la clase obrera, que lo aprecia a razón de veinte mil ejemplares por mes, que no son nada, para lo bien que está hecho ese periódico», y más adelante «Tampoco he escrito. Estoy por terminar una antología [Crónicas de Cuba], y después, sí, después escribiré». El tono se vuelve deseante en la reunión de los sujetos de su ficción: «Una historia que empezara con Juan Eugenio, 
siguiera con Willie, abarcara a Ángel y a Renato y a Mauricio» (2007: 104-107). Como explica en «La novela geológica», el desafío consiste en lograr una historia única reuniendo personajes repartidos entre cuentos publicados («Un kilo de oro», «Fotos», «Corso») y borradores que seguirá trabajando hasta su muerte («Uncle Willie won the war», «Juan se iba por el río»). La microsociedad de personajes argentinos es un proyecto incompleto, suspendido en los dilemas frente a la mezcla de la ficción con la vida, dilatado en busca de formas aptas para narrar el nuevo centro de verdad abierto por las explosiones de 1969. La exploración de la conflictividad social del presente atravesado por el pasado y el futuro, mediante subjetividades vitalmente confundidas con hechos políticos, genera resonancias productivas del plan de Walsh en la novela argentina a comienzos del siglo XXI. Por debajo de la distancia evidente con respecto al límite de la representación autoimpuesto por el escritor comprometido en 1969, en ciertos episodios de la narrativa contemporánea asoman continuidades manifiestas con el núcleo poético-político que Walsh exploró en formas imprevistas de hacer novela.

En 2010 Piglia publica una novela que ficcionaliza y politiza la investigación, donde reverbera un comienzo casi invisible del novelazo fragmentario de Walsh: los siete cuentos que entre 1956 y 1964 forman la serie del comisario Laurenzi. La filiación es indicada por el protagonista de Blanco nocturno: como aquel justiciero de Walsh, Croce es el comisario que deja de serlo y sigue resolviendo el caso desde un manicomio con la ayuda de Emilio Renzi (personaje emblemático de Piglia, devenido protagónico en la línea del Daniel Hernández de Walsh, el aficionado al policial que escucha y narra los casos de Laurenzi). Antes que citar a Walsh, Borges y Pérez Zelaschi, el narrador de Piglia -como un lector que ha aceptado la suspensión de incredulidad- agranda el mundo ficcional leído en ellos, e incluye a Croce en la serie de colegas retirados como Leoni y Treviranus (personajes detectives de Pérez Zelaschi y de Borges respectivamente), iniciada con «Laurenzi, su viejo amigo, lo habían pasado a retiro y vivía en el sur» (2010: 95). Además de varios guiños en el interior del mundo de personajes (y en la sintaxis oral del relato), alude particularmente a Walsh el contrapunto final entre Croce y Renzi, al poner en cuestión (conversada) el restablecimiento del orden y la reconstrucción unívoca de una lógica del crimen. Como escenifica el juicio, detrás de trascendentales abstractos como justicia y verdad se juegan vidas de personas, el futuro de la zona y varias «cuestiones prácticas»: podría ser la moraleja evitada en la serie del ex comisario Laurenzi, capa germinal de la novela geológica de Walsh, homenajeada en la novela de Piglia.

La trama de vidas narradas mediante voces yuxtapuestas, que recrean la oralidad en torno a crímenes privados del pasado que involucran a la comunidad actual, y las tensiones entre verdad, ley, justicia exploradas en la reformulación de restos de géneros como el policial, dan forma a la novela de Carlos Gamerro, El secreto y las voces, que en 2002 inicia un ciclo unificado por personaje, lugar y época. La marca walshiana se diluye ante un montaje polifónico donde prevalece el dialogismo de Puig, tampoco ajeno a Piglia. La capacidad de escuchar y editar las voces de lugares fronterizos impulsa ciclos narrativos de diversa duración, que reúnen las capas del pasado violento de la conformación nacional desde 1810 con el pasado reciente de la memoria autobiográfica y el presente en el cual esa memoria sostiene la escritura. Las voces organizan la historia del país tramada en partes menores, al localizarse en lugares como Malihuel en el ciclo de Gamerro o, en las series de Walsh, un colegio para huérfanos irlandeses en la zona rural de Buenos Aires, los pueblos de la pampa húmeda por los que deambula Laurenzi, o el Río de la Plata como insólito paso a caballo de Juan hacia lo ajeno. 

Hernán Ronsino, con un preciso homenaje a Operación masacre desde el epígrafe, que toma un fragmento de prosa seca referido a la parte principal del suceso reconstruido por Walsh: el final del capítulo 24, cuando luego de «La matanza» (capítulo 23) los policías creen dar el tiro de gracia a Livraga al dispararle en la cara y el brazo, y se retiran dejándolo vivo en el basural de José León Suárez (Walsh 2009: 72-77). Se trata de la escena originaria de la investigación, el nudo de disturbio que buscó recomponer Walsh luego de entrevistar a Livraga y ver la cara agujereada del fusilado que vive (este oxímoron titula el capítulo 11, que condensa el material con el que inició la campaña periodística en diciembre de 1956). La estructura de Glaxo, organizada en cuatro capítulos narrados por sendos personajes en fechas significativas de la historia que desordenan la cronología $(1973,1984,1966,1959)$, dispone al final la revelación del enigma que conecta la intriga del presente de los personajes con su participación en el fusilamiento estatal investigado por Walsh, en la voz del comisario Ramón Folcada, tres años después de haber fallado en la operación: «Cuando pase el tren no voy a fallar como fallé esa noche en el basural de Suárez. Y porque fallé esa noche en el basural de Suárez quedó vivo ese negro peronista. Y ahora hay un libro» (Ronsino 2009: 90-91). Incluyendo la alusión puesta en la voz del victimario, la ficción da forma a lo increíble, para reconstruir no solo los crímenes del pasado sino su impunidad en los presentes futuros. Esta vigencia novelística de Walsh supera los prejuicios estéticos y políticos en torno al reparto que cataloga el libro canónico como no-ficción.

En su siguiente novela, Lumbre (2013), Ronsino extiende el ciclo pueblerino y familiar vinculado a crímenes de la historia reciente, y vuelve a homenajear la virulencia narrativa de Walsh. Las versiones de dos personajes centrales (el Viejo y Pajarito), sobre una estafa contra el pueblo en una colecta, solo acuerdan en que «como sucede siempre, se había manipulado los sueños de los más débiles para legitimar un engaño. Como en la política, se atrevió a decir esa noche Pajarito Lernú». Una escena decisiva del anteúltimo capítulo podría verse en continuidad con la novela de las lenguas de oprobio leída por Link en Walsh, que actualiza capas literarias de la serie de mataderos que en la tradición argentina transforma los sentidos estéticos y discursivos de la política (Echeverría, Ascasubi en el XIX, Bustos Domecq, O. Lamborghini en el XX, entre otros donde se inserta explícitamente Walsh, al corregir a Echeverría en su crónica de 1967 titulada «El matadero»). La violencia juvenil de muchos contra uno es narrada con frases tan breves como fotos sonoras -«se excitan, entre risas, gritos y ladridos»- cuyo ritmo remeda el vértigo del fusilamiento narrado en Operación masacre: «Un cuerpo sometido -ahoracorre liberado en medio de los pastizales» (Ronsino 2013: 226, 253). A la par del evidente influjo de Saer, bajo las formas narrativas practicadas por Ronsino funcionan Operación masacre, Cartas/Fotos, «Corso», las crónicas de Panorama.

Como la novela proyectada de Walsh, estas novelas recientes narran los conflictos de sujetos vitalmente fundidos con hechos sociales y políticos reconstruidos. La marca de Walsh se resignifica en la ficción contemporánea; las limitaciones señaladas en su época bajo moldes estéticos y políticos pueden leerse como tramitación de la resistencia moral de la novela y del declarado agotamiento de la ficción. Mejor que insistir en el abandono de la literatura por el compromiso público, la lectura actual puede reconsiderar el aporte de esa forma múltiple que fue tomando «la idea de la novela en sí, su posibilidad» (según la frase de nuestro epígrafe); diversas novelas del 2000 verifican que el trabajo realizado por Walsh, como anotaba en enero del 69, se notaría efectivamente más adelante. Los 
dilemas del presente han generado una novela diferida, cuyas marcas emergen en poéticas narrativas que, a principios del siglo XXI, expanden modos de representación de lo político abiertos por aquella proyección que se encaró con las limitaciones de la política y la estética. Las posiciones de los sujetos ante la ley y la justicia, según sus acciones discursivas en el presente atravesado por el pasado, formuladas en la disputa polifónica de la memoria colectiva, organizan la imaginación de la novela de Walsh y reaparecen en los ciclos novelísticos del espacio bonaerense donde los crímenes del pasado siguen activos.

Como advierte Dalmaroni (2005: 119), además del corpus de autor o de época «el pasado nos ofrece desde siempre la discronía constitutiva de la historicidad cultural, que obliga [...] a estudiar temporalidades superpuestas». Esto sería particularmente complejo en el caso de quien no puede ser ubicado en una coyuntura ni emplazado en una categoría. La novela de Walsh no vista en 1969 es contemporánea en el sentido de Agamben: sostiene con raro coraje la mirada fija en su tiempo para percibir su oscuridad «como algo que le incumbe y no cesa de interpelarlo». Walsh es siempre contemporáneo no porque su obra o figura sean pasibles de monumento sino porque su novela proyectada está en condiciones de transformar el tiempo, dividir e interpolar el presente en los otros tiempos, enfatizar momentos de la historia corridos de periodizaciones consensuadas. $\mathrm{Si}$, como a fines del 68 consignaba CGT, 1969 presentó la exigencia de empezar de nuevo, tal recomienzo abarca la oscuridad del presente de las décadas siguientes, desde que «el origen no se sitúa solamente en un pasado cronológico: es contemporáneo al devenir histórico y no cesa de funcionar en este» (Agamben 2010).

A comienzos del siglo XXI, cuando la formulación de proyectos «se ha vuelto una gran preocupación contemporánea» en economía, política, cultura (Groys 2014: 69, 75), el novelazo de Walsh sería un proyecto que desde su gestación no está pensado para completarse. Brinda la oportunidad de ver el presente desde la perspectiva del futuro porque deja abierta la brecha entre ambos, con la potencia que poseen esos proyectos menos estéticos que poéticos, porque nunca se llevan a cabo y no generan un producto final. La aclaración siguiente de Groys es particularmente adecuada para leer a Walsh en 2010 y después:

Pero de ninguna manera esto significa afirmar que tales proyectos -incompletos e imposibles de realizar- sean completamente excluidos de la representación social, incluso si ellos no se resincronizan con el curso general de las cosas a través de un resultado específico, exitoso o no.

Hacia 1969 se complejiza la mitología autoral de Walsh basada en la lentitud, porque se vuelve apremiante el desplazamiento del oficio de escritor por el periodismo gremial y la militancia política; al mismo tiempo (y sin tiempo) en la intimidad de la escritura sigue planeando una novela ambiciosa. La diacronía abierta hacia atrás por novelas argentinas de comienzos del XXI permite visualizar que el oficio no ha sido abandonado sino complejizado en el uso de formas, géneros, medios, incluyendo la intuición de una novela entre las series narrativas. Esa novela no era Rosendo aunque estaba allí y en los ciclos legibles entre la obra y los papeles personales, como también en los ciclos novelísticos de futuros escritores argentinos. La novela de Walsh es geológica con respecto a la literatura contemporánea: como la resaca que deja la ola, se hace legible por debajo del boom latinoamericano y del novelazo argentino, casi medio siglo después de 1969, con la fuerza de lo lento y lo incompleto. 


\section{BIBLIOGRAFÍA}

AA.VV., Los diez mandamientos (sel. LUGONES, Piri), Buenos Aires: Jorge Álvarez, 1966.

A.C., «El prólogo de la novela», Primera Plana, año V nº 248, 26 de septiembre al 2 de octubre de 1967, p. 77.

AGAMBEN, Giorgio, «¿Qué es lo contemporáneo?», Otra parte. Revista de letras y artes, nㅡ 20, otoño de 2010, pp. 78-90.

ALTAMIRANO, Carlos, «Memoria del '69», Punto de Vista. Revista de Cultura, n 49, Buenos Aires, agosto de 1994, pp. 5-7.

BAJTIN, Mijail, Teoría y estética de la novela. Madrid: Taurus, 1991.

BARTHES, Roland, La preparación de la novela. Notas de cursos y seminarios en el Collège de France, 1978-1979 y 1979-1980. Buenos Aires: Siglo XXI, 2005.

CRESPO, Bárbara, «El lector en el relato testimonial: 'En lo que a mí atañe, es cosa suya`», El Matadero. Revista crítica de literatura argentina, año I, no 1 (Número de homenaje a Rodolfo Walsh), Buenos Aires, ILAR, FFyL, UBA, 1998, pp. 77-96.

DALMARONI, Miguel, «Historia literaria y corpus crítico (aproximaciones williamsianas y un caso argentino)», Boletín del Centro de Estudios de Teoría y Crítica literaria, № 12, Rosario, FHyA, UNR, diciembre de 2005, pp. 109-128.

EL MUNDO (s/firma), «RODOLFO WALSH. Le Reclaman una Novela», $2^{a}$ sección, 8 de octubre de 1967, p. 43.

FERNÁNDEZ, Macedonio, Museo de la novela de la Eterna (Primera novela buena). Obras completasTomo VI. Buenos Aires: Corregidor, 1975.

GAMERRO, Carlos, El secreto y las voces. Buenos Aires: Grupo Editorial Norma, 2002.

GILMAN, Claudia, Entre la pluma y el fusil. Debates y dilemas del escritor revolucionario en América Latina. Buenos Aires: Siglo XXI, 2003.

GROYS, Boris, Volverse público. Las transformaciones del arte en el ágora contemporánea. Buenos Aires: Caja Negra, 2014.

JOZAMI, Eduardo, Rodolfo Walsh. La palabra y la acción. Buenos Aires: Norma, 2006.

LINK, Daniel, «Rodolfo Walsh: vida y obra», Tramas para leer la literatura argentina, año I, ํo 1 (Rodolfo Walsh), Córdoba, CILS, 1999, pp. 19-30.

-_-_ Cómo se lee y otras intervenciones críticas. Buenos Aires: Norma, 2003.

LITTAU, Karin, Teorías de la lectura. Libros, cuerpos y bibliomanía. Buenos Aires: Manantial, 2008.

PIGLIA, Ricardo, Blanco nocturno. Barcelona: Anagrama, 2010. «Prólogo» y «Nota de esta edición», WALSH, Rodolfo. Cuentos completos (ed. y pról. PIGLIA, Ricardo). Buenos Aires: Ediciones de la Flor, 2013, pp. 9-17, 525.

RONSINO, Hernán. Glaxo. Buenos Aires: Eterna Cadencia, 2009.

Lumbre. Buenos Aires: Eterna Cadencia, 2013. 
TERÁN, Oscar. Nuestros años sesentas. La formación de la nueva izquierda intelectual en la Argentina 1956-1966. Buenos Aires: Puntosur, 1991.

Historia de las ideas en la Argentina. Diez lecciones iniciales. Buenos Aires: Siglo XXI, 2012.

VIÑAS, David, Cosas concretas. Buenos Aires: Tiempo Contemporáneo, 1969.

WALSH, Rodolfo. ¿Quién mató a Rosendo? Buenos Aires: Ediciones de la Flor, 2003.

Ese hombre y otros papeles personales (ed. LINK, Daniel). Buenos Aires: Ediciones de la Flor, 2007.

Operación masacre seguido de La campaña periodística (ed. FERRO, Roberto). Buenos Aires: Ediciones de la Flor, 2009.

\section{NOTAS}

1. Este artículo retoma con otro sesgo algunas líneas de mi libro Una novela invisible. La poética política de Rodolfo Walsh, actualmente en prensa en la editorial Eduvim de Argentina.

2. Para la contextualización histórica y biográfica puede verse Link (1999: 25-27) y Jozami (2006: 121-123, 152-154, 193-201, 231-236). Las prevenciones antiintelectuales se resumen en una frase de Ongaro referida a los cuentos de Walsh, según la anécdota oral que anota en noviembre del 69: «'No entiendo nada', parece que dijo Raimundo. ‘¿Escribe para los burgueses?' [...] me molestó porque yo sé que tiene razón, o que puede tenerla» (Walsh 2007: 158).

3. Altamirano (1994: 7) recuerda «un encuentro de obreros, estudiantes e intelectuales» en Córdoba en 1970, donde «la epifanía de un tiempo nuevo» se modula en el «lenguaje inaudito», que sobrepasaba el estereotipo del discurso de propaganda, «un lenguaje a la vez orgulloso y desenvuelto, que transmitía firmeza y ductilidad». Tales marcas lingüísticas aparecen en la renovación periodística que Walsh practica en medios diversos, sobrepasando estereotipos políticos y estéticos (en CGT, Primera Plana o Panorama).

4. La débil inserción de los intelectuales en el Estado o en un proyecto grupal los dota de una movilidad propia que los vuelve activos en la sociedad y en la política, «disponibles para comunicar su práctica intelectual con la política, donde hallaron al dios de la revolución capaz de reforzar sus proyectos culturales». Hacia 1969 alcanza su culminación el «movimiento politizador de la cultura», que "fue siguiendo los mismos clivajes de radicalización que los enfrentamientos políticos» (Terán 1991: 151-155, 159). Esa movilidad decide el efecto perturbador que provocan en Walsh las prevenciones de Ongaro sobre su literatura (ver nota 2).

5. «El arreglo con él preveía una novela que podía estar lista de octubre a diciembre de 1968, y de la que apenas tengo escritas unas treinta páginas. // El tiempo que debí dedicar a la novela lo dediqué, en gran parte, a fundar y dirigir el semanario de la CGT. // Jorge Álvarez tendría, pues, en este momento, el derecho a decir que lo he estafado. Eso desde luego me preocupa sin que por otra parte- me sienta convencido de haber obrado mal. // La estafa, por otra parte, no es excesiva. Le entregué dos libros -una antología cubana y la reedición de Operación Masacre». Luego calcula cuánto reduciría la deuda "un tercer libro sobre el caso Rosendo» (Walsh 2007: 123-124; la doble barra indica punto y aparte).

6. Al margen de la explosión editorial que señala Gilman en 1967 (cuando se publica en Buenos Aires Cien años de soledad y se duplica la producción de libros con respecto al año anterior), cabe agregar que el mismo año aparece Museo de la novela de la Eterna, la gran novela póstuma de Macedonio Fernández. Montaje de fragmentos que multiplican la clasificatoria de la novela en diálogo con el lector, la primera mitad de Museo está hecha de prólogos (v. gr. «Prólogo a la 
eternidad», «Prólogo a mi persona de autor», «A los críticos», «Prólogo, también», «Otro prólogo», «Prólogo que se siente novela»), y sigue un intertítulo que desarma los prejuicios taxonómicos vigentes en 1967: «Éstos ¿fueron prólogos? Y ésta ¿será novela?» (Fernández 1975: 269-270). En una carta de 1964, Walsh recomendaba al crítico norteamericano Donald Yates la traducción y edición de la obra de Macedonio, «presentarlo al público norteamericano, como ya has presentado a Borges» (2013: 500).

7. La tapa del número 33 exhibe el factor popular y la vigencia de su difusión masiva: «Un millón de ejemplares / 33 semanas junto al pueblo». Muchos titulares de CGT condensan la coyuntura y nombran acontecimientos que serán históricos. Los sucesos de mayo a septiembre de 1969 que se llamarán cordobazo/rosariazo pueden leerse seis meses antes, en tapa del número 24 (10 de octubre de 1968) que adopta modulación de consigna: «Ganar la calle el 15». La convocatoria plural -obrera, estudiantil, cívica- define actores sociales y lugares de acontecimientos: «De 0 a 24 Horas. Movilización Popular en Defensa del Petróleo y los Obreros en Huelga. Estudiantes, fuerzas cívicas y trabajadores: un acto en cada plaza, cada facultad y cada fábrica». Las mayúsculas del original destacan la axiomática que orienta el discurso de la revista. El número 48, de julio de 1969, aplica el color azul de la portada al desafío directo que el título dirige al presidente golpista golpeado por la movilización popular: «Aquí Estamos, Gral. Onganía». Tres números después deja de haber color y es evidente un desmejoramiento tipográfico; desde septiembre del 69 a febrero del 70, en sus últimos cinco números, la revista se hace clandestina, como indica el paréntesis agregado a la leyenda de identidad: «Órgano oficial de la CGT de los argentinos (en la clandestinidad)». La consigna lanzada para 1969, en el anteúltimo número del 68, resulta válida para los modos en que la cultura va a narrar ese año: «1969: Hay que empezar de nuevo». La colección completa del periódico está digitalizada en el sitio de la Federación Gráfica Bonaerense: http://www.cgtargentinos.org/. Consulta: 10/01/2016.

8. Si Operación masacre es el modelo para la construcción de los personajes como trabajadores asesinados, sobre esa atención a las subjetividades Rosendo practica un cambio, que Crespo (1998: 86-87) estudia en la distribución de partes de cada libro. «Las personas» y «Los hechos» son las partes primera y segunda de Operación en sus cuatro ediciones; en la serie periódica del semanario CGT aparecen invertidas, y en ¿Quién mató a Rosendo? se funden como primera parte («Las personas y los hechos») a la que sigue «La evidencia», que en Operación era la tercera parte, y aquí deja el lugar de la tercera para «El vandorismo». El orden del relato sería la diferencia fundamental entre Rosendo y Operación: si en este «el peso de la argumentación recaía en presentar como víctimas a civiles inocentes», en aquel «el periodista comprometido que acepta la responsabilidad de dirigir un semanario obrero, concibe un enfoque distinto para construir a sus personajes», cuyas historias de vida resultan inseparables del contexto, superando la separación entre personas y hechos.

9. Los apuntes tomados de un libro de historia política (Alem: informe sobre la frustración argentina de César Augusto Cabral, 1967) serían parte de la documentación que complejizaba el proyecto de novela, probablemente vinculados al proceso de escritura de «Juan se iba por el río», último cuento de Walsh, ubicado hacia 1880: Juan Eugenio Duda cruza a caballo el Río de la Plata fugándose de Buenos Aires, y queda indeterminado antes de llegar cuando las aguas suben (2007: 273-276).

10. En su reflexión sobre el corpus crítico a partir de Williams, Dalmaroni (2005: 121-122, 124) construye una estructura del sentir que llama Buenos Aires, 1969, por la sincronía en la aparición de libros decisivos para la literatura argentina contemporánea, como Cicatrices de Juan José Saer, Boquitas pintadas de Manuel Puig, El fiord de Osvaldo Lamborghini, Los poemas de Sydney West de Juan Gelman, ¿Quién mató a Rosendo? de Rodolfo Walsh, Fuego en Casabindo de Héctor Tizón. El corpus indicaría el momento en que surge la tradición posborgiana dominante, visible en las poéticas que en las dos últimas décadas del XX resultan controversialmente consensuadas como alta literatura. 
11. «La inclusión del caso de Puig pero sobre todo del de Walsh precisa de argumentos específicos que no podemos desarrollar aquí» (Dalmaroni 2005: 122, nota 23).

12. En el análisis del arte contemporáneo de Groys (2014: 10-15), «la actitud estética presupone la subordinación de la producción artística al consumo artístico». El sujeto de la actitud estética sería un amo cuyo esclavo es el artista (como ficcionaliza Walsh en «Fotos» en 1965, y Puig en The Buenos Aires Affair en 1973); incluso la «politización del arte puede ser fácilmente combinada con su estetización».

13. «La capacidad de contar elípticamente está definida por una cualidad, digamos antinovelística: la brevedad, la rapidez, la temporalidad quebrada, es decir, la capacidad de construir la historia a partir de mínimas situaciones, escenas fugaces, líneas de diálogo, cartas, elipsis» (Piglia 2013: 11). El énfasis valorativo sería contraparte positiva de la carencia señalada por la recepción inmediata de Un kilo de oro (la falta de una forma extensa de narración ficcional que pueda llamarse novela).

14. Link define tres novelas posibles: el ciclo de irlandeses (los tres cuentos $\mathrm{y}$ «El 37») como novela de aprendizaje, «Fotos» y «Cartas» como novela del campo bonaerense, «Corso», «La mujer prohibida» $\mathrm{y}$ «La máquina del bien y del mal» como novela de las lenguas de oprobio.

15. La pesquisa lingüística de Walsh reformula esa marca de la novela moderna que Bajtin encuentra en Stendhal o Balzac: «la combinación de lo histórico y lo social-público con lo particular, e incluso con lo estrictamente privado [...]; la mezcla de la intriga privada con la política y financiera; del secreto de Estado con el secreto de alcoba; de la serie histórica con la cotidiana y biográfica» (Bajtin 1991: 115-116, 397). La solapa de Cosas concretas de David Viñas, novelón publicado en 1969 por Tiempo Contemporáneo, ubica al autor en un linaje mayor formulado en la mezcla de series y géneros: «una amplia saga balzaciana en la que distintos niveles de escritura (ensayo, crítica, narración, reportaje, crónica) se organizan en función de la dialéctica entre biografía privada e historia política que obsesiona al autor». El redactor de «La novela geológica» adjudica a Walsh una obsesión del mismo tenor, con un verbo significativo (que subrayamos): «Walsh ha empezado a desvivirse por que 'mis historias particulares no contradigan la historia general de los argentinos'» (2007: 112).

\section{RESÚMENES}

En 1969, Rodolfo Walsh (1927-1977) desplaza propósitos estéticos que había priorizado cinco años atrás (cuando dejó el periodismo para escribir ficción) y trastoca la figuración autoral afirmada previamente. El acercamiento a la militancia en el vértigo cultural y vital de fines de los 60 (en el semanario del sindicalismo opositor en 1968-69, desde 1970 en agrupaciones armadas) oblitera el uso subjetivo del tiempo y desacomoda la autoexigencia de morosidad, pero no interrumpe tareas de escritor. Al querer encauzar la velocidad de la revolución en el oficio meticuloso de leer/escribir, Walsh genera una poética que excede la ficción y la estética. Contigua al trabajo periodístico-político surge la imaginación de una novela, entre series de cuentos y crónicas, entre tensiones de los papeles personales recuperados en 1996, en la estructura de ¿Quién mató a Rosendo? al convertir en libro la campaña periodística. Aunque ese libro sincronice en 1969 a Walsh con Puig, Saer, Tizón y otros en el corpus emergente de la tradición posborgeana de la literatura argentina, la poética de Walsh desborda los soportes impresos y la expectativa de lo nuevo allí fechada, y ofrece una novela posible desfasada del 69, que funciona en la literatura argentina contemporánea, de Ricardo Piglia a Hernán Ronsino. 
In 1969, Rodolfo Walsh (1927-1977) changes his esthetic purposes highlighted five years ago (when he left journalism for writing fiction) and disrupts his own authorial figuration already established. The approach to political militancy in the cultural and vital vertigo of late 60 s (in the weekly paper of the opposing syndicalism in 1968-69, since 1970 in armed groups) obliterates the subjective use of time and unsettles the self-imposed slowness, but it don't interrupt the tasks of a writer. Wanting to channel the speed of revolution in the meticulous craft of read/write, Walsh generates a poetics that exceeds fiction and aesthetics. Contiguous to journalistic and political work, the imagination of a novel arises, between sets of stories and chronicles, between tensions on personal papers recuperated in 1996, in the framework of ¿Quién mató a Rosendo?, that converts the press campaign in a book. Although this book of 1969 allow to synchronize Walsh with Puig, Saer, Tizón and others, in the emerging corpus of the pos-Borges tradition in argentine literature, the poetics of Walsh go beyond the printed media and the expectation of the new dated in 1969; it offer an outdated novel that works in argentine contemporary literature, from Ricardo Piglia to Hernán Ronsino.

En 1969 Rodolfo Walsh (1927-1977) déplace les propos esthétiques qui avait priorisé cinq ans avant (quand il abandonné le journalisme afin d'écrire fiction) et ainsi il modifie la figuration de l'auteur affirmée auparavant. Le rapprochement au militantisme dans le vertige culturel et vital de la fin des années 1960 -notamment dans l'hebdomadaire du syndicalisme d'opposition en 1968-69, et depuis 1970 dans des groupes armés- oblitère l'usage subjectif du temps et déstabilise l'auto-exigence de retard, mais il n'interrompt pas les tâches d'écrivain. Attaché à l'objectif de canaliser la vitesse de la révolution dans le métier méticuleux de lire/écrire, Walsh génère une poétique qui excède la fiction et l'esthétique. À côté de son travail journalistique-politique émerge l'imagination d'un roman, mélangé entre ses contes et ses chroniques, se rendre évident aussi bien dans ses papiers personnels (récupérés en 1996), que dans la structure de ¿Quién mató a Rosendo? Bien que ce livre positionne à Walsh en synchronie avec Puig, Saer, Tizón et d'autres auteurs conformant en 1969 un corpus émergent de la tradition posborgeana de la littérature argentine, la poétique de Walsh déborde les supports imprimés et l'expectative du nouveau de l'époque, et elle offre un roman déphasé de l'année 1969, qui fonctionne encore dans la littérature argentine contemporaine, de Ricardo Piglia à Hernán Ronsino.

\section{ÍNDICE}

Palabras claves: Autor, estética, poética, revolución, temporalidad.

Keywords: Author, esthetics, poetics, revolution, temporality.

Mots-clés: Auteur, esthétique, poétique, révolution, temporalité

\section{AUTOR}

\section{JUAN PABLO LUPPI}

ILH/UBA- CONICET

pabloluppi@hotmail.com 